\title{
Differential Activation of the Caudate Nucleus in Primates Performing Spatial and Nonspatial Working Memory Tasks
}

\author{
Richard Levy, Harriet R. Friedman, Lila Davachi, and Patricia S. Goldman-Rakic \\ Section of Neurobiology, Yale University School of Medicine, New Haven, Connecticut 06510
}

The caudate nucleus is part of an anatomical network subserving functions associated with the dorsolateral prefrontal cortex (DLPFC). The aim of the present study was to investigate whether the metabolic activity in the striatum reflects specific changes in working memory tasks, which are known to be dependent on the DLPFC, and whether these changes reflect the topographic ordering of prefrontal connections within the striatum. Local cerebral glucose utilization (LCGU) rates were assessed in the striatum by the ${ }^{14} \mathrm{C}$-2-deoxyglucose method in monkeys that performed a spatial (delayed spatial alternation), a nonspatial (delayed object alternation) visual working memory task, or tasks that did not involve working memory, i.e., a visual pattern discrimination or sensorimotor paradigm.

The results show a topographic segregation of activation related to spatial and nonspatial working memory, respectively. The delayed spatial alternation task increases LCGU rates bi- laterally by $33-43 \%$ in the head of the caudate nucleus, where efferents from the dorsolateral prefrontal cortex project most densely. The delayed object alternation task enhances LCGU rates bilaterally by $32-37 \%$ in the body of the caudate nucleus, which is innervated by the temporal cortex. The visual pattern discrimination task similarly activated the body of the caudate, but in a smaller region and only in the right hemisphere.

These findings provide the first evidence for metabolic activation of the caudate nuclei in working memory, supporting the role of this nucleus as a node in a neural network mediating DLPFC-dependent working memory processes. The double dissociation of activation observed suggests an anatomical and functional segregation of cortico-striatal circuits subserving spatial and nonspatial cognitive operations.

Key words: primates; caudate nucleus; prefrontal cortex; 2-deoxyglucose; metabolic activity; working memory
Although the function of the striatum remains largely enigmatic, many illnesses affecting striatal function, such as Parkinson's and Huntington's diseases, are characterized by a disruption of mental processes necessary for the organization, execution, and control of goal-directed behaviors, i.e., executive functions (Albert et al., 1974; Pillon et al., 1986; Taylor et al., 1986; Owen et al., 1992). Although the neostriatum receives projections from almost all association cortices, it is particularly linked to the dorsolateral prefrontal cortex (DLPFC) (Kemp and Powell, 1970; Goldman and Nauta, 1977; Yeterian and Van Hoesen, 1978; Selemon and Goldman-Rakic, 1985; Yeterian and Pandya, 1991; Eblen and Graybiel, 1995), the cortical area most closely associated with executive functions (Milner, 1964; Luria, 1966; Schallice, 1982; Goldman-Rakic, 1987; Fuster, 1989). Numerous studies indicate that the DLPFC plays an essential role in working memory, one of these executive functions (Goldman-Rakic, 1987; Jonides et al., 1993; McCarthy et al., 1994; Smith et al., 1996). Because the DLPFC projects to the caudate nucleus, this nucleus has been considered a necessary component of a working memory network. Indeed, striatal neurons exhibit sustained activity, during the delay period of working memory tasks, resembling that observed in prefrontal neurons (Alexander et al., 1986; Schultz and Romo, 1988; Hikosaka et al., 1989; Apicella et al., 1992). Furthermore, lesions or dysfunctions of the caudate nucleus in human and

Received Aug. 28, 1996; revised Feb. 6, 1997; accepted Feb. 21, 1997.

This work was supported by grants from Fyssen, Philippe Foundations, and Association Huntington-France to R.L., and by National Institute of Mental Health Grants MH44866 and MH38546 to P.G.-R.

Correspondence should be addressed to Dr. Patricia S. Goldman-Rakic, Section of Neurobiology, Yale University School of Medicine, 333 Cedar Street, New Haven, CT 06510.

Copyright (C) 1997 Society for Neuroscience $\quad 0270-6474 / 97 / 173870-13 \$ 05.00 / 0$ nonhuman primates have been reported to produce impairments in the delayed response tasks that assess working memory (Battig et al., 1960; Divac et al., 1967; Butters and Rosvold, 1968; Freedman and Oscar Berman, 1986; Partiot et al., 1996).

Physiological and lesion studies support the idea of segregated anatomical and functional domains within the caudate nucleus (Divac et al., 1967; Rolls, 1994). These studies imply that the head of the caudate is preferentially involved in spatial cognition, whereas posterior portions, more specifically the caudal part of the body and the tail of the caudate, are more engaged in discrimination processes. Because anatomical studies indicate that terminals from distinct prefrontal regions are topographically segregated within the striatum (Selemon and Goldman-Rakic, 1985), the domain-dependent segregation within the caudate nucleus may be related to the functional compartmentalization of the DLPFC. Indeed, within the DLPFC, the principal sulcus is involved in working memory for spatial location, whereas the inferior convexity and the lateral-orbital prefrontal cortex may contribute to visual nonspatial working memory (for review, see Goldman-Rakic, 1987).

These findings lead to the expectation that separate subareas of the caudate nucleus make specific contributions to spatial and nonspatial (or object features) visual (processing within) working memory, depending on its connections with specific areas of prefrontal cortex. To test these hypotheses, we have measured levels of metabolic activity within the striatum while monkeys performed working memory tasks either in the spatial or the nonspatial (object) domain. Local cerebral glucose utilization (LCGU) rates, assessed by the 2-deoxyglucose (2-DG) method (Sokoloff et al., 1977), were used as an index of striatal metabolic activity. LCGU rates of monkeys performing working memory 
tasks were compared with those of monkeys engaged in control tasks that required identical perceptual and motor skills but little or no working memory load.

\section{MATERIALS AND METHODS}

\section{Animals}

Sixteen male rhesus monkeys (Macaca mulatta), from 2 to 4 years old, were used in this study. The animals were housed in separate cages in animal rooms under standard conditions of temperature, relative humidity, air exchange, and day/night cycles. They were fed a diet of monkey chow and fruit adjusted to stabilize their performances; water was available ad libitum. This study was performed in accordance with the Guide for the Care and Use of Laboratory Animals adopted and promulgated by the National Institutes of Health.

\section{Behavioral tasks}

The training procedures for each of the tasks used here have been described previously (Friedman and Goldman-Rakic, 1988, 1994) and are only reviewed briefly in the following section. Monkeys were trained to sit in a primate chair and habituated to a modified Wisconsin General Testing Apparatus (WGTA). The WGTA contained a wooden test tray $(22 \times 50 \mathrm{~cm})$ with two recessed wells for rewards. The testing sessions in the WGTA were given in a darkened and sound-shielded room while a 90 $\mathrm{dB}$ white noise was generated. Monkeys were taught to displace two similar cardboard plaques $(8 \times 8 \mathrm{~cm})$ or two different objects (a blue wooden box, $6.5 \mathrm{~cm}$ square $\times 3 \mathrm{~cm}$ high, and a green cylinder, $6.5 \times 8 \mathrm{~cm}$ high) that covered the wells to obtain a food reward. They were then assigned to their specific task. The learning phase was tailored for each individual monkey to facilitate the acquisition of the rules. Monkeys were initially trained on their task using short delays $(1-5 \mathrm{sec})$ and short session lengths $(20 \mathrm{~min})$. Once a monkey demonstrated proficiency on its task ( $\geq 90 \%$ correct in 100 trials), the delay per trial, the number of trials per session, and the length of session were increased until the animal performed the task $>90 \%$ correct during a $45-50$ min test period, as required for the 2-DG protocol.

Working memory tasks (Fig. 1). Nine monkeys performed the working memory tasks. Six of them performed a spatial working memory task, delayed spatial alternation (DSA). The three remaining animals were assigned a nonspatial working memory task, delayed object alternation (DOA). Both tasks have working memory contingencies because they required the monkey to maintain an internal representation of the immediately preceding stimulus to provide the correct response. However, they differed in their explicit demands; in the DSA task, the spatial location of the stimuli (right or left) guided the behavior, whereas in the DOA task, the features of objects (shape, size, and color) were the relevant information, and the spatial position of the objects had to be disregarded.

The DSA task started with both wells baited and covered with identical plaques and out of view of the monkey. On the first trial, the monkey displaced one of the two plaques and obtained a reward; the screen was then lowered during the delay period $(5,12$, or $30 \mathrm{sec}$; two monkeys were assigned to each of these three delay conditions). Thereafter, only the well not selected on the preceding trial was baited, thus, the previous selection must be recalled to select the appropriate well and consistently obtain rewards.

In the DOA task, the general procedure was similar to that described for the DSA task. Thus, as in the DSA condition, information about the immediately preceding response must be used to guide the response on a trial-to-trial basis. Nevertheless, to prevent monkeys from adopting a spatial strategy, the spatial position of the objects was pseudo-randomly governed (Gellerman, 1933), and only the object features were relevant for correct performance. The DOA task also differed from the DSA task in that all animals were trained on a $12 \mathrm{sec}$ delay period. The training necessitated several steps, including, at first, a simple object discrimination reversal task using a criterion of $90 \%$ correct in 60 trials before reversing the reward contingencies. The number of trials to reversal was then decreased in stages until one-trial alternation was achieved.

Nonworking memory tasks (Fig. 2). Seven monkeys were given control tasks; three monkeys performed a visual pattern discrimination (VD) task, and four others performed a sensori-motor control (SMC) task.

The VD task relied on associative memory but not on working memory, because monkeys learned a stimulus-response association that did not vary from trial to trial and from day to day. This task consisted of discriminating between two visual stimuli that were shown simultaneously

\section{WORKING MEMORY TASKS}

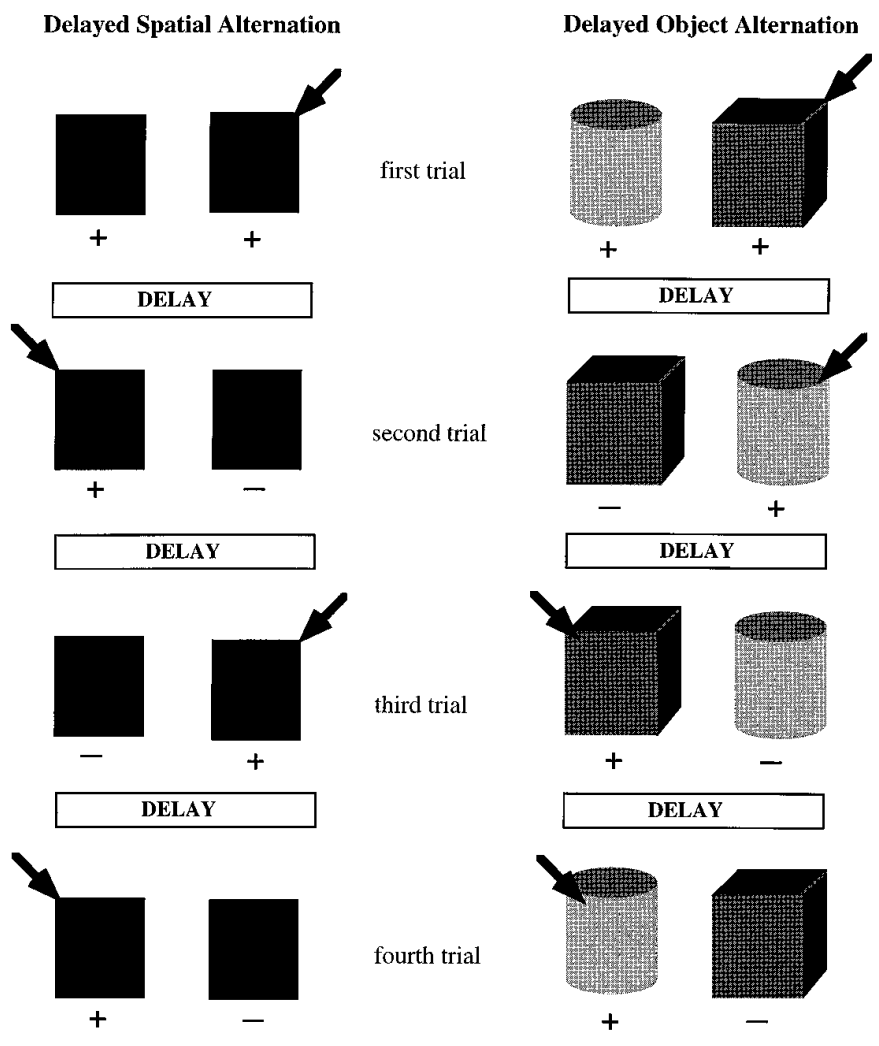

Figure 1. Working memory tasks. In these two tasks, the information guiding a correct response changed from trial to trial, and the monkey was required to update this information (i.e., to maintain an internal representation of the immediately preceding trial). In Delayed Spatial Alternation, after a delay, the monkey had to displace alternately a left or right plaque to retrieve a reward. Rewards were hidden by two identical plaques. In Delayed Object Alternation, the monkey had to alternate its choices between two objects (different in color, shape, and size) from trial to trial to obtain rewards. The same two objects were presented throughout the session and from day to day. To prevent monkeys from adopting a spatial strategy, the objects were positioned according to a pseudorandom order. The + sign indicates that a reward is hidden behind the plaques or objects (reinforced stimulus), whereas the - sign signifies the absence of positive reinforcement; arrows indicate the correct response (except for the first trial, in which either choice is correct).

on each trial. Stimuli were a plaque showing a white plus sign on a black background and a plaque showing a white square on a black background. Only the plus sign card covered the reward within a same session and from day to day. The spatial position of the plaques was pseudo-randomly sorted (Gellerman, 1933), rendering a spatial strategy counterproductive to rewarded performance. A $12 \mathrm{sec}$ intertrial delay separated all trials.

In the SMC task, one or both wells were baited and covered or not by two identical plaques. The animal was always permitted to retrieve the bait on each trial. Thereafter, the screen was lowered for $12 \mathrm{sec}$ during an intertrial interval. Thus, the sensory stimuli and the motor responses were similar to those present in all other tasks. Because the response is not based on the learning of an association or recall of the immediately preceding trial, explicit memory processing was not required.

\section{2-DG procedures}

Preparation. The 2-DG method was performed according to Sokoloff et al. (1977). All monkeys received arterial and venous catheters while they were anesthetized with a mixture of nitrous oxide and halothane gas in conjunction with local anesthetics. In 12 cases, the animals received catheters several hours before the 2-DG experiment and sat in the primate chair for at least $2 \mathrm{hr}$ to ensure recovery from anesthesia before 


\section{NON WORKING MEMORY TASKS}
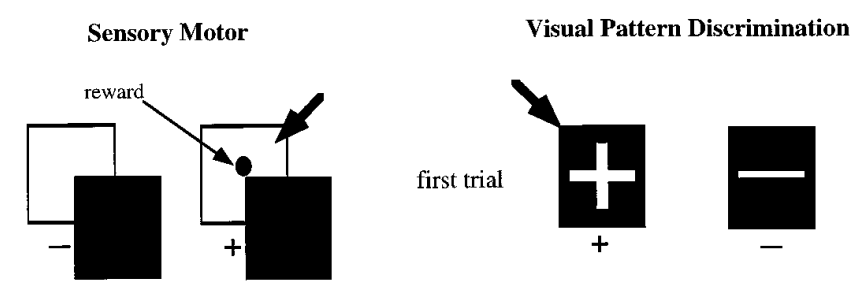

INTERTRIAL INTERVAL
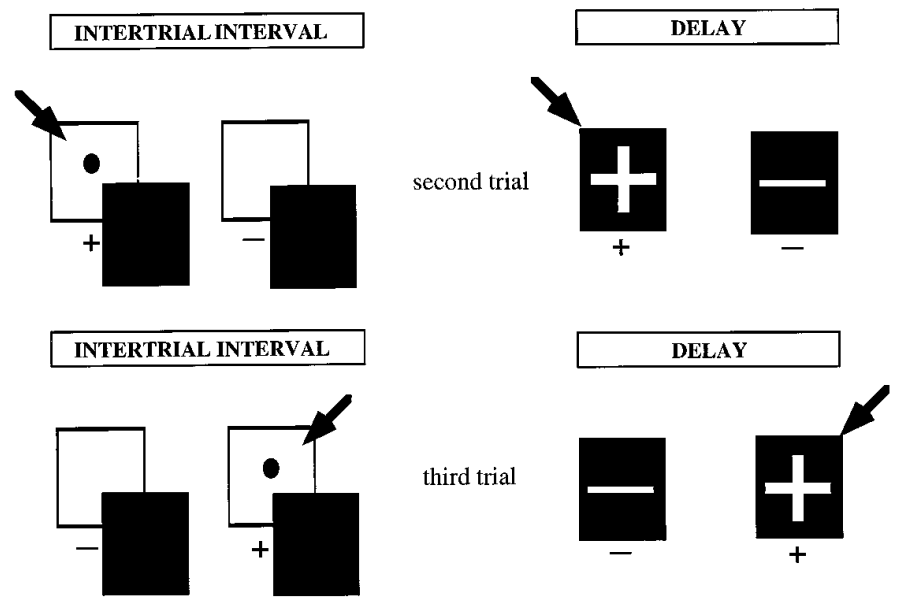

Figure 2. Sensorimotor and associative memory tasks. In the Sensory Motor condition, memory was not required either because the reward was in sight at the response phase (Fig. 2) or because all stimuli were baited (data not shown). An intertrial interval separated each trial, and there was no relationship between trials. In the Visual Pattern Discrimination condition, the monkey had to learn an association between a stimulus (the + sign card) and the reward. This association did not vary from trial to trial and from day to day. The + sign indicates that a reward is hidden behind the plaques or objects (reinforced stimulus), whereas the - sign signifies the absence of positive reinforcement; arrows indicate the correct response.

behavioral testing. In the remaining cases $(n=4)$, catheters were inserted $24 \mathrm{hr}$ before the 2-DG injection.

Experimental session. Approximately 3-5 $\mathrm{min}$ into the test session, monkeys were injected with ${ }^{14} \mathrm{C}-2-\mathrm{DG}(100 \mu \mathrm{Ci} / \mathrm{kg}$ in $1 \mu \mathrm{Ci} / 10 \mu \mathrm{l}$ sterile saline, 50-60 mCi/mm) (American Radiolabeled Chemicals, St. Louis, MO) followed by a saline flush. Arterial blood samples were taken at timed intervals over the next $45 \mathrm{~min}$. Test performances (the percent of correct trials and the total number of trials) were recorded. At the end of the session, the monkeys were injected with a lethal dose of sodium pentobarbital.

\section{Tissue processing}

Monkeys were first perfused intracardially with $3.3 \%$ paraformaldehyde. The brains were rapidly removed, sectioned into blocks, and frozen by immersion in isopentane $\left(-40^{\circ} \mathrm{C}\right)$. Blocks were then stored at $-70^{\circ} \mathrm{C}$ until processed. Sections $(20 \mu \mathrm{m}$ thick $)$ were cut at $-22^{\circ} \mathrm{C}$ on a cryostat (Hacker Instruments, Huntingdon, UK). Three consecutive sections were saved every $400 \mu \mathrm{m}$ throughout the brain. They were collected on cold coverslips, rapidly dried on a hot plate, taped to cardboard, and exposed to x-ray film (SB5, Kodak, Rochester, NY) for 5-10 d, together with a set of plastic ${ }^{14} \mathrm{C}$ standards $(0-1.08 \mathrm{Ci} / \mathrm{gm}$; Amersham, Arlington Heights, IL).

\section{Blood glucose and ${ }^{14} \mathrm{C}$ levels}

Fourteen arterial blood samples taken during the $45 \mathrm{~min}$ 2-DG test were centrifugated, and $20 \mu \mathrm{l}$ plasma samples were analyzed for glucose concentration (Beckman Glucose Analyzer II) and ${ }^{14} \mathrm{C}$ concentration (Beckman scintillation counter). Integrated arterial plasma-specific activities derived from the blood concentration curves were used to convert tissue ${ }^{14} \mathrm{C}$ concentration to LCGU rates, as described by Kennedy et al. (1978).

\section{Image analysis}

Autoradiograms of sections and attached sets of ${ }^{14} \mathrm{C}$ standards were digitized using a computerized video-image processing system. The computer used these standards to quantify radioactivity by translating pixel gray values to ${ }^{14} \mathrm{C}$ radioactivity levels. These levels were converted to LCGU rates using the integrated plasma-specific activities obtained for each monkey.

Striatal samples selected for $L C G U$. Seven different anatomical levels in the frontal plane, from the most rostral portion of the head of the caudate nucleus (level 1) to the most posterior part of the striatum encompassing the genu and the tail of the caudate nucleus (level 7), were selected for analysis (Fig. 3). At each level, three to six sections were selected for each monkey, based on the quality of the tissue. Image analysis was performed on both left and right caudate nucleus, putamen, and ventral striatum. Two different methods of analysis were performed, as described in the following sections (Fig. 4).

Two methods for segmentating the striatum. To maximize the probability of detecting changes relative to the activation of a particular corticostriatal circuitry, we have used two different methods for subdividing the striatum at seven different levels in the rostro-caudal axis. The first method, the "sample" analysis, allowed us to select the best sample within a given area (i.e., at distance from tissue artifacts) and ascertain that the LCGU measurement was performed in the subarea selected (centrally located in the subregion of interest). This segmentation permitted us to determine whether any change in subregional 2-DG uptake for a given behavioral task was superimposed on the topographic mapping of the projections from cortical areas known to be crucial for the behavior in question. However, because of the relative heterogeneity of the labeling in the striatum, one can argue that this measurement may not reflect the global LCGU rate in that particular subarea. By contrast, the second method, the "regional" analysis, was performed to take into account the possible heterogeneity of the labeling by obtaining a global measurement of LCGU rate within a given region. However, this analysis may include tissue artifacts such as holes or wrinkles and encompass borderline regions where it is difficult to differentiate one region from another. The two LCGU measurement techniques serve as reciprocal controls for each other, allowing us to detect methodological biases in case of a discrepancy between the two techniques for the same subarea.

"Sample" analysis. LCGU rates were measured in several square samples of equal sizes within the striatum (Fig. 4,1). These "boxes" were distributed within the striatum to cover all areas of interest. From level 1 to level 5 , the caudate nucleus was segmented into nine subareas according to a grid based on three $x$ - and three $y$ - axes. There were three dorsal (dorsolateral, dorsocentral, and dorsomedial); three central (centrolateral, central, and centromedial); and three ventral (ventrolateral, ventrocentral, and ventromedial) subareas. In each of these subareas, a box centrally located was taken for LCGU measurement. At a given level, all results obtained from all sections for a particular subarea were averaged to obtain a mean for that subarea. It was then possible to determine the means for a dorsal, a central, and a ventral region of the caudate nucleus at the level studied by pooling the three subareas included in each of these regions. By pooling all regions, means for the left and the right caudate nuclei were obtained. At levels 6 and 7, because of the small area analyzed, only one box, centrally located, was taken. At level 3, the most ventral part of the striatum corresponding to the nucleus accumbens ("ventral striatum") was analyzed by taking a lateral and a medial sample per side for a given section (Fig. 4,1). LCGU rates in the putamen were measured only at level 4 in the putamen, using the same method of segmentation described for the caudate nucleus.

"Regional" analysis. The sections used in the "sample" analysis were also used here. In this method, from level 1 to level 5, three caudate subregions were delineated (dorsal, central, and ventral) (Fig. 4,2). These three regions corresponded to the dorsal, central, and ventral regions of the first analysis. However, in this analysis, LCGU rates were measured over the entire surface of the delineated region. To delineate a region, the external boundaries of the caudate nucleus were drawn. Then, at each level, a line linking the dorsal pole to the ventral pole of the nucleus was drawn along the dorso-ventral axis and used as a basis for segmenting the caudate nucleus into approximately equal dorsal, central, and ventral regions (as in Fig. 4). To clearly dissociate these regions one from another, a buffer zone of $2 \mathrm{~mm}$ was interposed between each region. Thus, the surface analyzed for each region consisted of an area limited by 


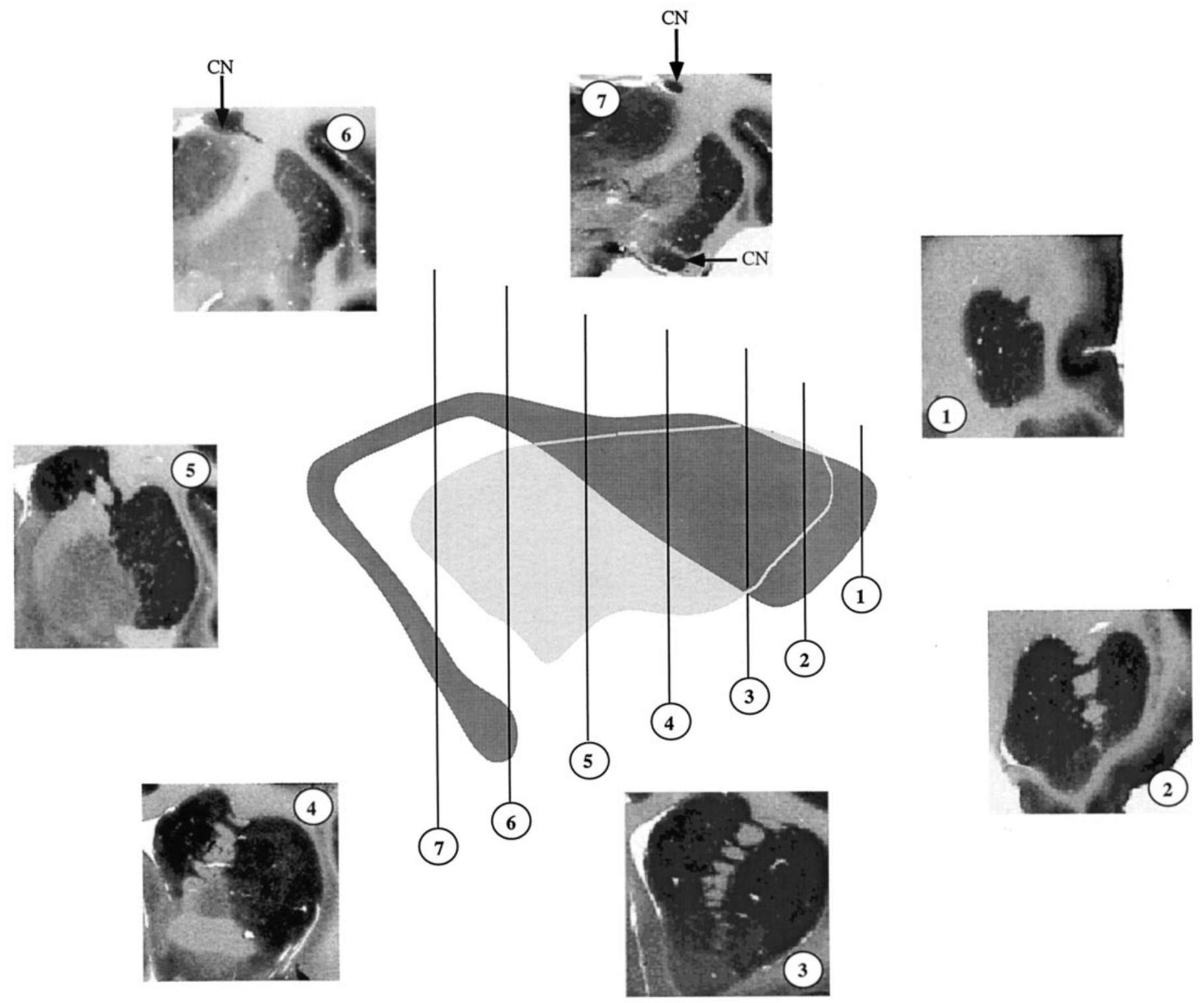

Figure 3. Levels selected for the image analyses. Seven levels, from the rostral to the caudal parts of the striatum, were selected for LCGU analysis. This schematic lateral view representation of the striatum in the center of the figure displays the anterior-posterior levels selected in each animal. The dark gray image represents the caudate nucleus, whereas the light gray area is the putamen. Autoradiograms from one monkey are shown at each of the seven levels. Note that the scale is not applicable from one photograph to another.

the caudate nucleus boundaries and the buffer zone. As for the first analysis, a mean for the caudate nucleus in each hemisphere was obtained for each section by pooling the results of the three regions. At levels 6 and 7 , the caudate nucleus was not segmentated and, therefore, a global measurement of LCGU was taken on each side for each section.

\section{Statistical analysis}

The major goal of this study was to determine whether working memory tasks influenced glucose utilization in discrete regions of the striatum. Thus, our main analyses compared LCGU rates in the striatum of monkeys performing the tasks that engaged working memory with striatal LCGU rates in the striatum of monkeys performing the tasks that did not. These analyses were done using a MANCOVA. Additional examination of significant differences in LCGU rates $(p<0.05)$ with regard to particular striatal regions of interest was performed using Tukey's test for post hoc comparisons. The covariance model was used to control for the individual differences in overall brain metabolism and, thus, to factor out unwanted individual effects. Left and right medial geniculate bodies were selected as the covariant structures, because these thalamic auditory nuclei were not likely to be differentially influenced by the tasks owing to the presence of the same white masking noise during all experiments (Friedman and Goldman-Rakic, 1988). Indeed, no statistically significant difference between groups was observed for the average LCGU rates in these nuclei (ANOVA). All statistical analyses were performed using a computer-based statistical package (SYSTAT, Sherman, IL).

Initially, mean LCGU rates from monkeys performing tasks requiring working memory (DSA and DOA tasks) were pooled into a single group (WORK group; $n=9$ ) and compared with mean LCGU rates obtained from monkeys performing nonworking memory tasks (SMC and VD tasks) that also formed a single group (CONT group; $n=7$ ). Next, to differentiate the respective influence of spatial and nonspatial working memory tasks on striatal 2-DG uptake, these two groups were compared separately with the CONT group. Finally, to evaluate the differences in LCGU rates among DSA, DOA, VD, and SMC tasks, these four groups were all compared with each other as specific planned comparisons within the same statistical analysis.

Results obtained from the two image analysis methods, i.e., "sample" and "regional" methods, were independently processed. Results from 

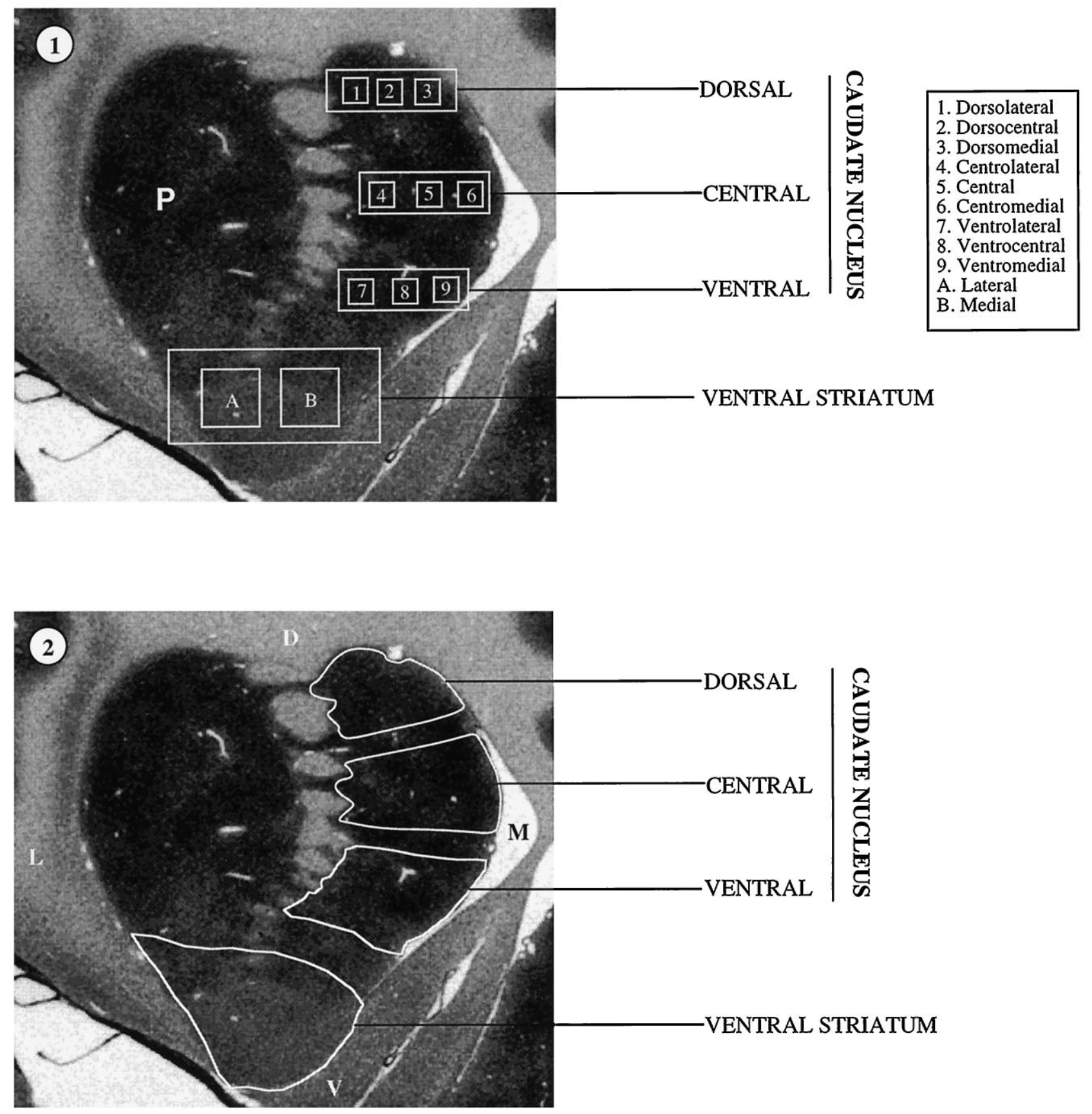

Figure 4. Example showing the two different methods of image analysis. Panels 1 and 2 are photographs from the same section taken at level 3 in a monkey performing the SMC task to illustrate the two different methods of analysis used in this study. The rationale for these two methods and additional methodological details are presented in Material and Methods. Panel 1 shows the "sample" method of image analysis. In this method, LCGU was measured in square samples centrally located in each of nine subdivisions of the caudate nucleus (as defined in the frame). These measurements were performed on three to six sections at each level for a given monkey. A mean LCGU rate was obtained by pooling equivalent samples from all sections at one level. For instance, left dorsolateral samples (box 1) from all sections at level 3 obtained from one monkey were averaged to obtain a mean LCGU rate corresponding to the left dorsolateral subarea at level 3. Thereafter, averages from the dorsal (boxes 1-3), central (boxes 4-6), and ventral (boxes 7-9) samples were pooled to obtain mean LCGU rates for the dorsal, central, and ventral subregions of the caudate nucleus, respectively. Finally, mean LCGU rates from these three regions were averaged to obtain a mean LCGU rate for the caudate nucleus. This procedure was applied to the left and right caudate nuclei separately. Mean LCGU rates for a given region were averaged across monkeys to obtain a group mean LCGU value for that particular region. In the second method of analysis ("regional" analysis, panel 2), instead of taking box samples, the caudate nucleus was divided into three regions (dorsal, central, and ventral), as shown. Measurements of LCGU rates were performed on the entire surface of the region of interest. Results were averaged for each region and across animals by the same method that was applied in the "sample" analysis. Note the decrease in the intensity of labeling according to a dorso-ventral gradient and the patchy zones of higher intensity in the dorsal regions. The dorso-ventral gradient observed in this figure was confirmed by the LCGU measurements in the CONT group, which showed a $24 \%$ difference between the dorsal region of the caudate nucleus (adjusted mean LCGU rates, $56 \pm 4.67$ ) and the ventral striatum (adjusted mean LCGU rates, $43.2 \pm 3.49$ ). $L$, Lateral border; $M$, medial border; $D$, dorsal border; $V$, ventral border; $P$, putamen. 
each anatomical level and cerebral hemisphere were analyzed separately. For each level, a two-factor ANOVA, using as parameters the cognitive tasks and the areas of interest, was performed on the average LCGU value \pm SEM for each subarea, region, and nucleus. Although increasing the probability of encountering type I errors, this method of statistical analysis was preferred to a single-variance analysis with repeated measures in which all anatomical levels were processed. Indeed, depending on the tissue availability, the number of subjects in each group varied with anatomical level, rendering difficult this latter type of statistical analysis.

All results for the striatum are expressed as means \pm SEM adjusted for the covariate and are taken directly from the MANCOVA.

\section{RESULTS}

On the 2-DG test date, the DSA group mean performance score was $88 \%$ correct, the DOA group mean score was $80 \%$ correct, and VD group mean score was $98 \%$ correct. These differences in performance among groups reflect the degree of difficulty in achieving criterion throughout the training sessions. By far, the DOA task was the most difficult, because it required more sessions on average than all other tasks (DOA, 6.7 months of training; DSA, 3.5 months; VD, 2 months), and the mean performance score was lower relative to the other tasks on the 2-DG test date as well as at the earliest stage of the training. On the 2-DG test day, the average number of trials completed by each monkey in the DOA, VD, and SMC tasks was $150 \pm 10$ trials. In the DSA group, three different delays were used (5, 12, and $30 \mathrm{sec}$ ). Therefore, the two monkeys performing the 12 sec delay task completed $150 \pm 10$ trials as the monkeys did in the three other groups. Monkeys on the $5 \mathrm{sec}$ delay task $(n=2)$ completed twice as many trials (300), whereas the two remaining monkeys on the $30 \mathrm{sec}$ delay task achieved $\sim 75$ trials.

\section{General pattern of labeling in the striatum}

In all monkeys, the pattern of labeling was heterogeneous within the striatum. The most striking pattern was a dorsal-ventral gradient of labeling (Fig. 4). For instance, in monkeys performing the SMC task, at level 3, there was a $25-30 \%$ difference in mean LCGU rates between the dorsal region of the caudate nucleus (higher LCGU rates) and the ventral striatum (lower LCGU rates). This dorso-ventral gradient was evident in all monkeys. In addition, in both the caudate nucleus and putamen, patchy zones of higher intensity were observed (Fig. 4). Although this pattern was seen at each level, it was more obvious at level 3 (the caudal part of the head of the caudate).

\section{Influence of working memory tasks on striatal 2-DG uptake}

The results obtained using the "sample" versus the "regional" method of 2-DG autoradiograph analysis were essentially the same. At striatal levels 1-4, 6, and 7, mean LCGU rates were found to be very similar to the two methods of image analysis (in no case were the differences within group between the two methods of image analysis $>10 \%$ ). Moreover, statistical analysis of the data provided similar results with each of the two methods. At level 5, the two methods of image analysis could not be compared, because the quality of the brain tissue was not suitable for the "sample" analysis in two monkeys in the CONT group and one monkey in the WORK group. Moreover, the "sample" analysis did not show any significant differences between the medial, central, and lateral subregions in the group comparisons. Therefore, we have chosen for the purpose of clarity to present only the results obtained in the "regional" analysis.

\section{Working memory (WORK) versus nonworking memory (CONT)}

Mean LCGU rates were higher throughout the caudate nucleus in the WORK group relative to the CONT group (Table 1). However, there were two distinct portions of the caudate nucleus wherein increased LCGU rates in the WORK group differed significantly from the CONT group (Table 1). The first was located in the rostral portion of the caudate nucleus from level 1 to level 3 (Table 1). Significant increases of $>30 \%(p<0.05)$ were found at level 1 in both the dorsal and central parts of the nucleus in the left hemisphere. In the right hemisphere, the increase at this level was significant $(p<0.05)$ only in the dorsal region. No significant differences were observed in the ventral regions of the caudate nucleus in either hemisphere. Increases ranged from 26 to $37 \%$ at caudate level 2 and were significant for each region of the left (dorsal, $p<0.005$; central, $p<0.01$; ventral, $p<0.01$ ) and right (dorsal, $p<0.005$; central, $p<0.01$; ventral, $p<0.01$ ) hemispheres. At level 3, the increases ranged from 22 to $27 \%$ and were significant in all neostriatal regions (dorsal, $p<0.05$; central, $p<0.05$; ventral, $p<0.05$ ) in the left hemisphere and in the dorsal $(p<0.05)$ and central $(p<0.05)$ regions in the right hemisphere. Again, there was no evidence of ventral region activation at this level in either hemisphere.

The second locus of increased 2-DG uptake was smaller and located more caudally. It encompassed the caudal part of the body (level 6 ) of the right caudate nucleus $(p<0.05)$. No significant increase was detected in the left hemisphere at this level (Table 1).

\section{$D O A$ and $D S A$ group comparisons}

Performance on the DSA and DOA tasks enhanced LCGU rates in two separate caudate regions (Table 2, Figs. 5-7). When compared with the group of monkeys performing the SMC task, the DSA condition significantly enhanced mean LCGU rates in the dorsal sector of the rostral head of the caudate nucleus at level 1 (DSA, $65.01 \pm 5.04 / \mathrm{SMC}, 41.28 \pm$ 6.67, $p<0.05)$ in the left hemisphere and in all regions of both hemispheres at level 2 (left dorsal: DSA, 74.04 \pm 3.5/SMC, $51.26 \pm 4.44, p<0.005$; left central: DSA, 72.57 $\pm 3.45 / \mathrm{SMC}, 51.3 \pm 4.57, p<0.05$; left ventral: DSA, $59.42 \pm$ 2.61/SMC, $43.69 \pm 3.46, p<0.01$ ) (right dorsal: DSA, $73.28 \pm$ 4.03/SMC $53.34 \pm 5.32, p<0.05$; right central: DSA, 72.39 \pm 4.53/SMC, $51.92 \pm 5.99, p<0.05$; right ventral: DSA, $59.69 \pm 3.53 / \mathrm{SMC}, 42.36 \pm 4.67, p<0.05)$. Another significant increase was found on the right in the caudal portion of the body of the nucleus al level 6 (DSA, $70.37 \pm 2.85 /$ SMC, $52.24 \pm$ $3.76, p<0.05)$. Although mean LCGU rates tended to increase from 5 to $30 \%$ in all other regions of the caudate nucleus, none of these increases reached statistical significance. Significant increases in mean LCGU rates were also observed when comparing the DSA group with the VD group in the dorsal (left: $\mathrm{VD}, 54.03 \pm 4.84, p<0.05$; right: VD, $49.8 \pm 5.81, p<0.05)$ and central (left: VD, $53.54 \pm 4.99, p=0.05$; right: VD, $49.97 \pm 6.54, p<0.05)$ parts of the caudate nucleus at level 2 . When the DSA group was compared with the combined CONT group (SMC + VD groups), significant increases in mean LCGU rates in the rostral caudate nucleus were similar to those observed in the DSA/SMC comparison except that the increase found in the right caudal part of the body was not significant (Fig. 5). Within the group of monkeys performing the DSA task, there was a tendency for LCGU rates to increase as the length of delay increased $(5,12$, and $30 \mathrm{sec}$.), but this was 
Table 1. Comparison between working memory and control conditions for mean LCGU rates in the caudate nuclei

\begin{tabular}{|c|c|c|c|c|}
\hline \multirow[b]{2}{*}{ Levels } & \multicolumn{2}{|l|}{ Left CN LCGU } & \multicolumn{2}{|l|}{ Right CN LCGU } \\
\hline & $\begin{array}{l}\text { WORK } \mu \mathrm{mol} / \\
100 \mathrm{gm} / \mathrm{min}\end{array}$ & $\begin{array}{l}\mathrm{CONT} \mu \mathrm{mol} / \\
100 \mathrm{gm} / \mathrm{min}\end{array}$ & $\begin{array}{l}\text { WORK } \mu \mathrm{mol} / \\
100 \mathrm{gm} / \mathrm{min}\end{array}$ & $\begin{array}{l}\mathrm{CONT} \mu \mathrm{mol} / \\
100 \mathrm{gm} / \mathrm{min}\end{array}$ \\
\hline \multicolumn{5}{|l|}{1 (Head) } \\
\hline Dorsal & $62.35 \pm 4.18^{*}$ & $46.49 \pm 4.75$ & $63.55 \pm 3.72^{*}$ & $50.41 \pm 4.23$ \\
\hline Central & $63.27 \pm 4.24^{*}$ & $48.38 \pm 4.82$ & $62.96 \pm 6.13$ & $50.76 \pm 4.69$ \\
\hline Ventral & $52.37 \pm 3.72$ & $43.38 \pm 4.23$ & $51.42 \pm 3.61$ & $41.01 \pm 4.10$ \\
\hline \multicolumn{5}{|l|}{2 (Head) } \\
\hline Dorsal & $70.23 \pm 2.97^{* * *}$ & $52.21 \pm 3.37$ & $70.28 \pm 3.27^{* * *}$ & $51.47 \pm 3.72$ \\
\hline Central & $68.00 \pm 3.19^{* * *}$ & $51.94 \pm 3.63$ & $68.86 \pm 3.69^{* *}$ & $50.74 \pm 4.19$ \\
\hline Ventral & $56.02 \pm 2.40^{* *}$ & $44.31 \pm 2.73$ & $56.26 \pm 2.99^{* *}$ & $41.57 \pm 3.39$ \\
\hline \multicolumn{5}{|l|}{3 (Head) } \\
\hline Dorsal & $70.90 \pm 3.51^{*}$ & $55.98 \pm 4.30$ & $70.50 \pm 2.85^{*}$ & $59.09 \pm 3.49$ \\
\hline Central & $72.75 \pm 3.79^{*}$ & $59.76 \pm 4.64$ & $72.72 \pm 3.30^{*}$ & $60.51 \pm 4.04$ \\
\hline Ventral & $64.69 \pm 3.39^{*}$ & $52.66 \pm 4.15$ & $63.34 \pm 3.28$ & $54.48 \pm 4.02$ \\
\hline \multicolumn{5}{|c|}{4 (Head/body) } \\
\hline Dorsal & $71.31 \pm 5.86$ & $59.60 \pm 7.41$ & $72.64 \pm 5.70$ & $57.40 \pm 7.23$ \\
\hline Central & $74.32 \pm 5.98$ & $64.09 \pm 7.57$ & $74.85 \pm 5.55$ & $61.13 \pm 7.04$ \\
\hline Ventral & $59.75 \pm 5.03$ & $51.03 \pm 5.23$ & $60.20 \pm 4.89$ & $50.77 \pm 5.69$ \\
\hline \multicolumn{5}{|l|}{5 (Body) } \\
\hline Dorsal & $71.25 \pm 4.53$ & $61.75 \pm 5.74$ & $71.74 \pm 4.04$ & $60.85 \pm 4.66$ \\
\hline Central & $78.25 \pm 4.01$ & $68.24 \pm 5.08$ & $77.89 \pm 3.58^{*}$ & $63.94 \pm 4.14$ \\
\hline Ventral & $59.78 \pm 3.11$ & $56.61 \pm 3.93$ & $60.88 \pm 2.82^{*}$ & $50.47 \pm 3.25$ \\
\hline 6 (Body) & $68.28 \pm 3.58$ & $57.96 \pm 4.39$ & $73.38 \pm 3.02^{*}$ & $60.60 \pm 3.44$ \\
\hline 7 (Tail) & $60.18 \pm 2.85$ & $54.90 \pm 3.24$ & $58.10 \pm 2.25$ & $51.08 \pm 2.75$ \\
\hline
\end{tabular}

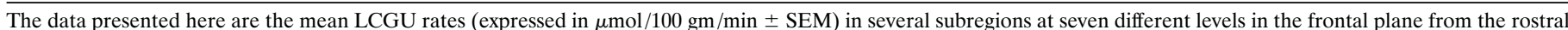

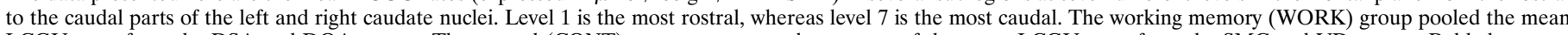

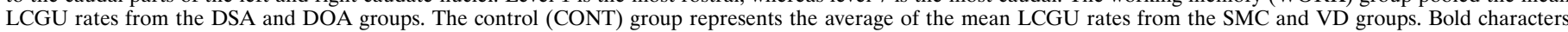

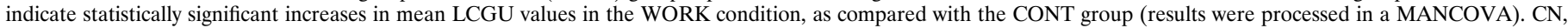
Caudate nucleus; LCGU, local cerebral glucose utilization; ${ }^{*} p<0.05$; ${ }^{* *} p<0.01$; ${ }^{* * *} p<0.005$.

not significant by regression analysis (length of delay by different regions of the caudate nucleus).

In contrast to the DSA task, the DOA condition significantly increased mean LCGU rates in the caudal region of the right caudate nucleus (level 6: DOA, $81.57 \pm 4.32 / \mathrm{SMC}, 52.24 \pm 3.76$, $p<0.005)$, and increases in the left caudate nucleus at the same level reached marginal significance (DOA, $79.83 \pm 5.84 / \mathrm{SMC}$, $54.26 \pm 5.42, p=0.059)$. Although mean LCGU rates tended to increase from 15 to $35 \%$ in all other regions of the caudate nucleus, none of these increases reached statistical significance. Differences between mean LCGU rates in the DOA and VD conditions were not significant at any level studied, although there was a tendency toward enhancement by DOA performance at levels 3-6 $(+15-20 \%)$. When the DOA group was compared with the combined CONT group (SMC + VD groups), mean LCGU rates were significantly increased at level 6 in both hemispheres (Fig. 6). A significant increase was also found in the central region (level 6) in the right hemisphere (DOA, 85.37 $\pm 5.93 /$ CONT, $63.86 \pm 3.91, p<0.05)$.

Thus, the changes in LCGU rates followed a rostro-caudal gradient, revealing a topographic double dissociation between the spatial and nonspatial working memory tasks compared with the control groups, whether or not the control task involved a memory component (VD or SMC task). In the DSA condition, the increase in mean LCGU rates was most prominent in the dorsal-central regions of the head of the caudate nucleus (Fig. 5), whereas in the DOA condition, mean LCGU rates were most elevated in the posterior regions of the body of the caudate nuclei (Fig. 6). These two conditions produced a "mirror reverse" pattern of LCGU activation throughout the an- terior-posterior axis (Fig. 7); in the DSA condition, the increase declined progressively along the anterior-posterior axis. By contrast, in the DOA condition, the increase declined throughout the posterior-anterior axis.

In addition, although comparisons between working memory and nonworking memory tasks revealed several differences between the left and right caudate nuclei (see above), within comparisons (paired $t$ tests) between the left and right hemispheres for the DSA and the DOA groups were not significant.

Compared with the SMC task, the VD condition demonstrated a single significant locus of increase $(>30 \%)$ in the right caudate nucleus at level $6(p<0.05)$. It is noteworthy that the LCGU rates in the VD group increased progressively from the rostral part of the head toward the caudal part of the body as did the DOA group.

\section{Mean LCGU rates in the ventral striatum and putamen}

LCGU rates were measured in the ventral striatum at a level where the cross-sectional area of the nucleus accumbens is largest (level 3; Fig. 4). No statistical differences were observed between groups (WORK vs CONT; DSA or DOA vs CONT; DSA, DOA, $\mathrm{VD}$, and SMC compared with each other) for the mean LCGU rates in this striatal region.

A similar analysis was performed in the putamen at one level (level 4). At this level, there was a general effect of working memory. When the WORK group was compared with the CONT group, a statistically significant increase $(p<0.05)$ of $>20 \%$ was found in the right dorsal region of the putamen. However, this was not a consistent finding, because when the data for all four tasks 
Table 2. Mean LCGU rates in the caudate nuclei in each of the four conditions

\begin{tabular}{|c|c|c|c|c|c|c|c|c|}
\hline \multirow[b]{2}{*}{ Level } & \multicolumn{4}{|c|}{ Left CN LCGU } & \multicolumn{4}{|c|}{ Right CN LCGU } \\
\hline & DSA & DOA & SMC & VD & DSA & DOA & SMC & VD \\
\hline \multicolumn{9}{|l|}{1 (Head) } \\
\hline Dorsal & $65.01 \pm 5.04$ & $57.32 \pm 7.65$ & $41.28 \pm 6.67$ & $53.12 \pm 7.27$ & $65.99 \pm 4.69$ & $58.44 \pm 7.11$ & $48.24 \pm 6.20$ & $53.41 \pm 6.77$ \\
\hline Central & $66.48 \pm 5.21$ & $56.78 \pm 7.92$ & $45.02 \pm 6.91$ & $52.99 \pm 7.53$ & $66.51 \pm 4.92$ & $55.78 \pm 7.53$ & $47.12 \pm 6.56$ & $55.72 \pm 6.56$ \\
\hline Ventral & $55.30 \pm 4.69$ & $46.14 \pm 7.10$ & $42.43 \pm 6.19$ & $45.03 \pm 6.75$ & $55.28 \pm 4.23$ & $43.31 \pm 6.42$ & $38.85 \pm 5.59$ & $44.26 \pm 6.10$ \\
\hline \multicolumn{9}{|l|}{2 (Head) } \\
\hline Dorsal & $74.04 \pm 3.5$ & $62.06 \pm 5.09$ & $51.26 \pm 4.44$ & $54.04 \pm 4.84$ & $73.28 \pm 4.03$ & $63.45 \pm 6.11$ & $53.34 \pm 5.04$ & $49.80 \pm 5.81$ \\
\hline Central & $72.57 \pm 3.45$ & $58.12 \pm 5.24$ & $51.30 \pm 4.57$ & $53.54 \pm 4.99$ & $72.39 \pm 4.53$ & $61.00 \pm 6.88$ & $51.92 \pm 5.99$ & $49.97 \pm 6.54$ \\
\hline Ventral & $59.42 \pm 2.61$ & $48.68 \pm 3.97$ & $43.69 \pm 3.46$ & $45.66 \pm 3.77$ & $59.69 \pm 3.53$ & $48.64 \pm 5.35$ & $42.36 \pm 4.67$ & $41.26 \pm 5.09$ \\
\hline \multicolumn{9}{|l|}{3 (Head) } \\
\hline Dorsal & $69.73 \pm 8.47$ & $73.21 \pm 7.23$ & $55.64 \pm 6.71$ & $56.36 \pm 6.74$ & $69.16 \pm 3.90$ & $73.17 \pm 5.70$ & $69.16 \pm 3.90$ & $57.05 \pm 5.32$ \\
\hline Central & $70.69 \pm 5.23$ & $76.82 \pm 7.66$ & $60.93 \pm 7.11$ & $58.65 \pm 7.15$ & $70.63 \pm 4.51$ & $76.81 \pm 6.60$ & $61.95 \pm 6.12$ & $59.14 \pm 6.16$ \\
\hline Ventral & $63.09 \pm 4.64$ & $67.85 \pm 6.80$ & $55.16 \pm 6.31$ & $50.19 \pm 6.34$ & $61.26 \pm 4.49$ & $67.42 \pm 6.57$ & $55.71 \pm 6.10$ & $53.03 \pm 6.13$ \\
\hline \multicolumn{9}{|c|}{4 (Head/body) } \\
\hline Dorsal & $69.12 \pm 8.47$ & $73.66 \pm 11.36$ & $61.82 \pm 10.73$ & $62.70 \pm 10.65$ & $68.28 \pm 7.82$ & $80.95 \pm 10.97$ & $56.06 \pm 14.71$ & $61.50 \pm 9.99$ \\
\hline Central & $70.08 \pm 8.50$ & $80.03 \pm 11.40$ & $69.84 \pm 10.77$ & $64.43 \pm 10.69$ & $69.74 \pm 7.57$ & $84.81 \pm 10.02$ & $59.71 \pm 13.70$ & $63.00 \pm 9.68$ \\
\hline Ventral & $59.60 \pm 5.55$ & $65.12 \pm 7.50$ & $58.54 \pm 10.07$ & $52.22 \pm 6.98$ & $56.39 \pm 6.16$ & $67.04 \pm 8.65$ & $54.44 \pm 10.25$ & $49.95 \pm 7.88$ \\
\hline \multicolumn{9}{|l|}{5 (Body) } \\
\hline Dorsal & $68.14 \pm 6.29$ & $76.91 \pm 8.63$ & $56.04 \pm 10.27$ & $65.08 \pm 7.99$ & $66.98 \pm 4.56$ & $79.95 \pm 6.11$ & $52.61 \pm 5.77$ & $68.81 \pm 5.73$ \\
\hline Central & $73.40 \pm 5.20$ & $86.76 \pm 7.16$ & $68.00 \pm 8.51$ & $67.79 \pm 6.61$ & $73.26 \pm 4.50$ & $85.83 \pm 6.04$ & $60.38 \pm 5.71$ & $67.28 \pm 5.66$ \\
\hline Ventral & $57.65 \pm 4.02$ & $63.32 \pm 5.52$ & $62.29 \pm 6.57$ & $52.32 \pm 5.11$ & $57.81 \pm 3.39$ & $66.15 \pm 4.54$ & $45.77 \pm 4.29$ & $55.29 \pm 4.26$ \\
\hline 6 (Body) & $62.33 \pm 3.99$ & $79.83 \pm 5.84$ & $54.26 \pm 5.42$ & $61.83 \pm 4.11$ & $70.37 \pm 2.85$ & $81.57 \pm 4.32$ & $52.24 \pm 3.76$ & $69.76 \pm 4.11$ \\
\hline 7 (Tail) & $59.50 \pm 3.37$ & $64.75 \pm 5.12$ & $49.52 \pm 4.64$ & $61.22 \pm 4.87$ & $57.28 \pm 2.85$ & $57.30 \pm 4.16$ & $47.27 \pm 3.86$ & $54.96 \pm 3.88$ \\
\hline
\end{tabular}

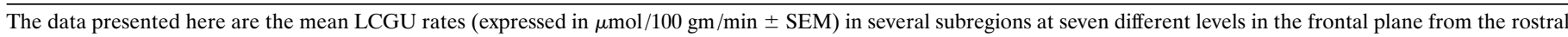

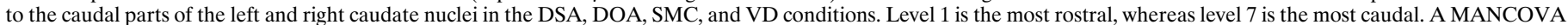
has been performed to the four conditions in the different striatal subregions to compare the four with one another. The results of this analysis are shown in Results.

were examined, there was no statistical difference in LCGU rates from dorsal, central, or ventral samples in either the left or the right putamen.

\section{DISCUSSION}

The present study demonstrates that tasks requiring working memory processing produced a significant enhancement in glucose utilization rates in specific subregions of the caudate nuclei. These results also reveal a relative topographic dissociation between the two working memory tasks: the spatial working memory condition significantly activated the dorsal and central regions of the head, whereas the nonspatial working memory task activated the caudal part of the body of the caudate nuclei more intensely. However, for both working memory conditions, LCGU rates tended to be enhanced beyond the boundaries of the significant loci of activation, suggesting that the caudate components for both working memory conditions were composed of a main locus of activation extended by longitudinal strips along the rostrocaudal axis. Moreover, the significant right caudal increase of 2-DG uptake in both VD and DOA conditions relative to the SMC task also suggests that the DOA task had an overriding commonality with the VD task requirements, possibly because of the visual processing elements in these two tasks. Importantly, the working memory tasks did not lead to a global enhancement of the corpus striatum, because significant increased glucose utilization was not detected in other striatal areas such as the rostral putamen, the ventral striatum, or other portions of the caudate nucleus. This topographic pattern of 2-DG uptake demonstrates that segregated cortico-striatal networks are involved in specific cognitive processes triggered by each task, referent to cortical innervation. However, it should be kept in mind that our analysis was a region-interest analysis, and we cannot exclude the possibility that there were areas of the striatum that were activated in the study by one or more tasks that escaped detection.

\section{Previous metabolic studies of working memory in human and nonhuman primates}

The 2-DG method has been shown to be an efficacious tool in the study of cerebral activation underlying visual working memory operations in the monkey, including metabolic enhancements in the DLPFC and inferior parietal cortex (Friedman and Goldman-Rakic, 1994), specific layers of the dentate gyrus, the CA1 and CA 3 fields of the hippocampus, the subiculum, the entorhinal and perirhinal cortices (Friedman and Goldman-Rakic, 1988; Davachi et al., 1995), and the mediodorsal and anterior thalamic nuclei (Friedman et al., 1990). As shown in the present study, the caudate nucleus must be considered an additional node in the same working memory network. Numerous functional imaging studies in normal humans have reported significant activation of the DLPFC by similar tasks without accompanying similar activations in the striatum (Jonides et al., 1993; Petrides et al., 1993; McCarthy et al., 1994; Smith et al., 1995; Courtney et al., 1996; Owen et al., 1996a,b; Smith et al., 1996). To our knowledge, this is the first report of increased metabolic activity in the striatum during working memory tasks, probably reflecting the higher spatial resolution of the 2-DG method in experimental animals. Alternatively, regional fluctuations of 2-DG uptake may reflect metabolic changes in the presynaptic element (Schwartz et al., 1979; Mitchell et al., 1989). If so, the enhanced activation found in the striatum is possibly a signature of the enhanced activity of the projection neurons activated by the task (in part, the prefrontal neurons). However, this may not be considered definitive, because 2-DG uptake has also been reported to follow changes in functional 

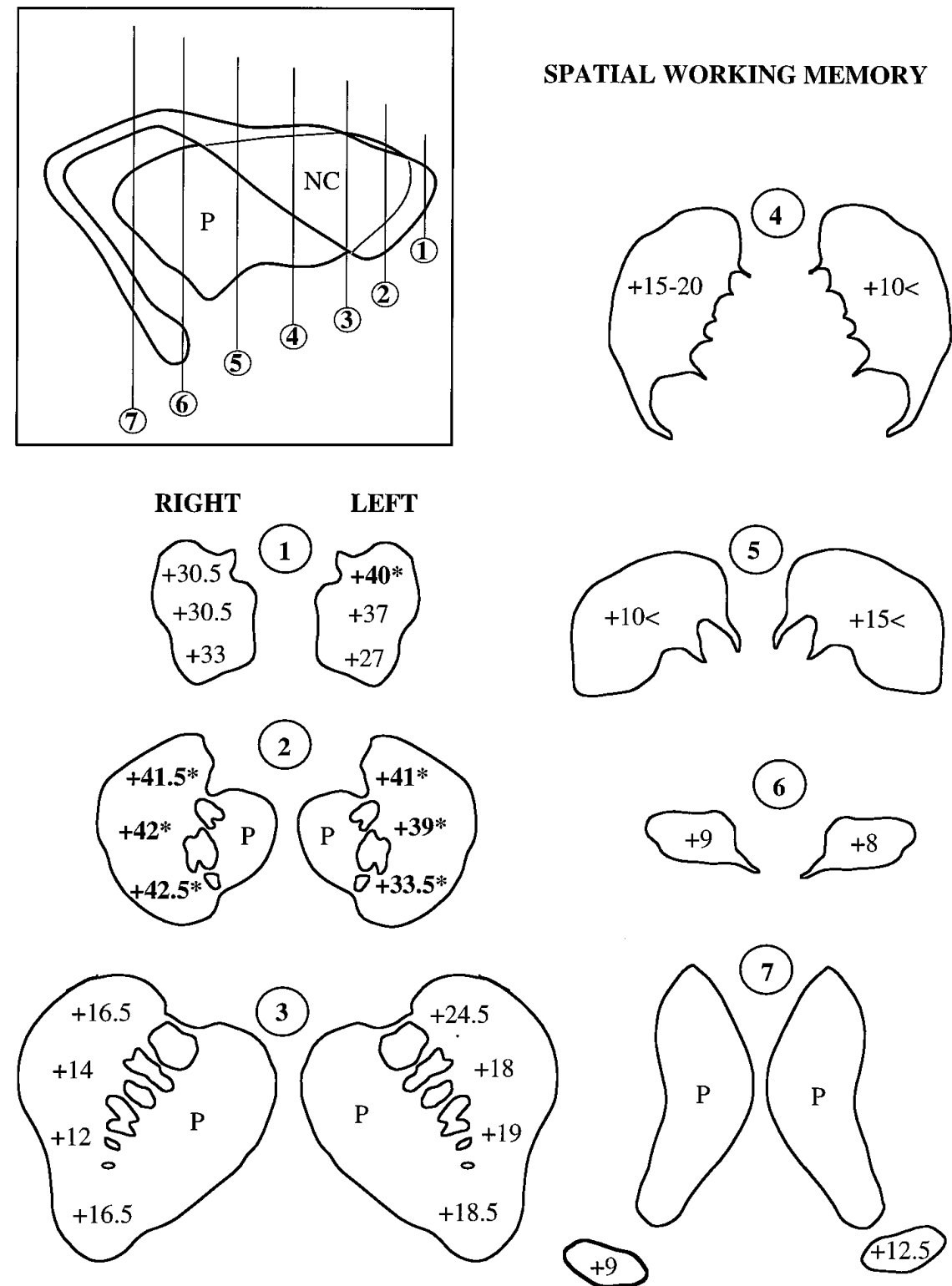

Figure 5. Percent increase in mean LCGU rates in the spatial working memory group, as compared with the control group. The percent increase in mean LCGU rates of the spatial working memory group (DSA) is shown at each level, as compared with a control group (CONT $=$ VD + SMC tasks). The results presented in this figure are from the "regional" analysis. Results from the dorsal, central, and ventral regions are shown at levels 1-3. At levels 4 and 5, ranges are shown for the overall increase in the dorsal, central, and ventral regions of the caudate nucleus. At levels 6 and 7, only one mean LCGU rate was obtained, because the caudate nucleus was not segmented into subregions at these levels. When shown, the putamen appears without numbers, because this structure was analyzed only at level 4 (the putamen is not shown at that level). Characters in bold and an asterisk indicate the statistically significant increase in mean LCGU rates $(p<0.05)$ in the DSA group relative to the CONT group. Note that "left" and "right" sides are flipped, because film autoradiograms are the "mirror" images of the actual sections. Also note that the scale differs from one level to another. $N C$, Caudate nucleus; $P$, putamen. activity of postsynaptic elements (Yarowsky et al., 1985). Finally, the long period of training as well as the 45 min performance period for the tasks used in our study probably activate more strongly the striatum than the test conditions in human metabolic studies, which are conducted over much briefer time periods.

Several functional imaging studies have reported hemispheric lateralization within the prefrontal cortex (and other associative cortices) between spatial (right activation) and nonspatial (left activation) visual working memories (Jonides et al., 1993; McCarthy et al., 1994; Smith et al., 1995). In our study, the spatial working memory task activated a larger area in the left caudate nucleus, whereas the object working memory activated a larger area in the right caudate nucleus, as compared with the control groups. However, within-group comparisons showed that these left-right differences were not significant.

\section{Corticostriatal networks for working and associative memories}

The present findings have provided functional validation of anatomically defined networks (Selemon and Goldman-Rakic, 1985; Alex- ander et al., 1986). The striatal subareas activated in spatial and nonspatial working memory tasks are nodes of a network linking them to cortical networks known to be crucially involved in the achievement of these tasks, the posterior parietal-prefrontal and inferotemporal-prefrontal pathways, respectively. Indeed, the present study indicates that this functional segregation of cortical regions may be extended to and maintained within the caudate nucleus. Separate cortical areas terminate in the caudate nucleus according to a pattern of longitudinal strips throughout the rostrocaudal axis (Goldman and Nauta, 1977; Selemon and GoldmanRakic, 1985; Yeterian and Pandya, 1991, 1995). However, although cortico-striatal projections are elongated throughout the rostrocaudal axis, frontal cortices such as Walker's areas 9 and 46, as well as posterior parietal areas $7 \mathrm{a} / 7 \mathrm{~m}$, do have more dense projections to the anterior portion of the caudate nucleus (Selemon and GoldmanRakic, 1985; Cavada and Goldman-Rakic, 1991; Yeterian and Pandya, 1991), whereas inferotemporal and other extrastriate visual cortices focus their densest projections in the most caudal portions of the caudate nucleus (Saint-Cyr et al., 1990; Webster et al., 1993; 


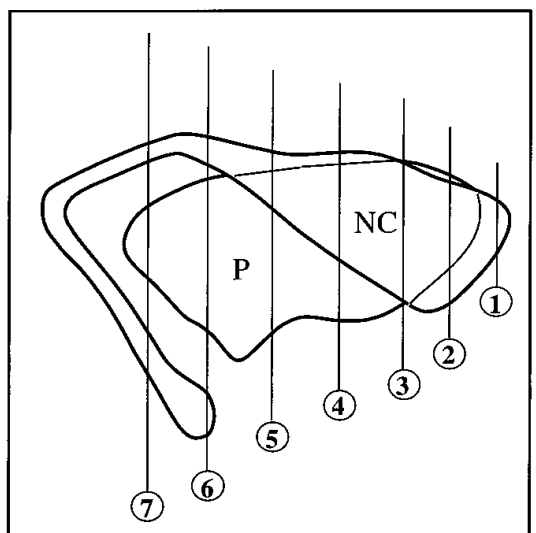

RIGHT
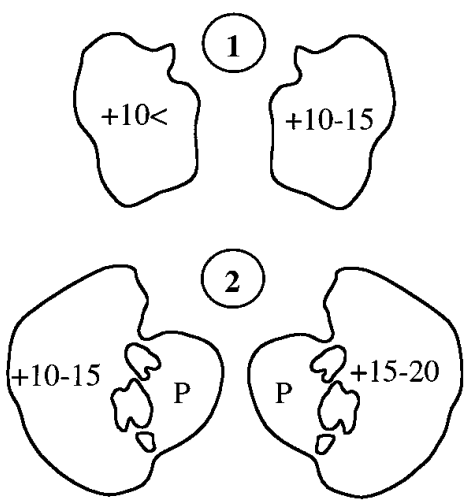

as compared with the control monkeys. The percent increase in mean LCGU rates of the nonspatial working memory group (DOA) is shown at each level, as compared with a control group $(\mathrm{CONT}=\mathrm{VD}+\mathrm{SMC}$ task$)$. Results from the dorsal, central, and ventral regions are shown at levels 3-5. At levels 1 and 2, ranges are shown for the overall increase in the dorsal, central, and ventral regions of the caudate nucleus. At levels 6 and 7, only one mean LCGU rate was obtained, because the caudate nucleus was not segmented into subregions at these levels. Characters in bold and an asterisk indicate the statistically significant increase in mean LCGU rates $(p<0.05)$ in the DOA group relative to the CONT group.

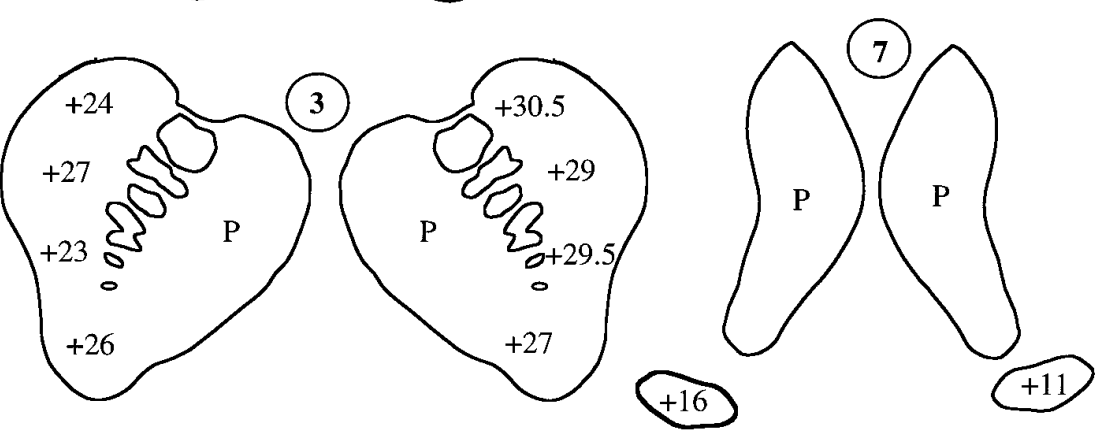

Yeterian and Pandya, 1995). In light of this topography, the enhancement of LCGU rates found in the dorsal and central portions of the rostral head of the caudate nucleus in the spatial working memory condition may likely correspond to the caudate regions where terminals from the DLPFC are the most concentrated. Furthermore, lesions of the anterodorsal portion of the head of the caudate nucleus, as of those in the principal sulcus, impair performance on spatial delayed response and delayed alternation tasks (Rosvold et al., 1958; Battig et al., 1960; Divac et al., 1967; Goldman et al., 1971; Cohen et al., 1972). Conversely, several nonspatial or nonworking memory tasks, e.g., object discrimination, color discrimination, or object reversal, are not disrupted by lesions of this portion of the striatum. Thus, the enhancement of 2-DG uptake in the dorsal and central portions of the head of the caudate nucleus in the spatial working memory condition is in accord with a broad literature on anatomical circuitry and lesions of the cortex and striatum.

In the present study, the VD task activated the posterior portion of the body of the caudate nucleus. Previous studies have shown that the posterior part of the caudate nucleus and the

\section{NONSPATIAL WORKING MEMORY}
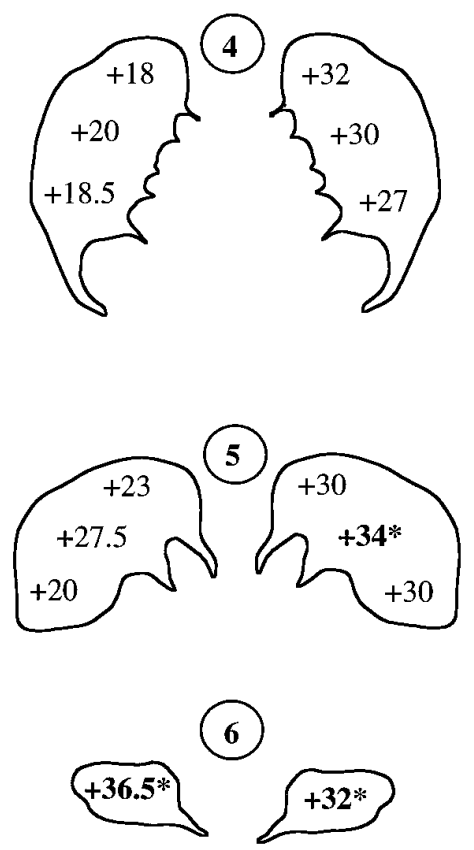

posteroventral putamen participate in VD and object discrimination tasks (Battig et al., 1960; Divac et al., 1967; Buerger et al., 1974). These striatal regions receive projections from the inferotemporal cortex (Saint-Cyr et al., 1990; Steele and Weller, 1993; Webster et al., 1993; Yeterian and Pandya, 1995), further suggesting that they are parts of a network involved in visual associative memory. The absence of increase in the tail during the VD task may be explained by the fact that neurons responding to physical patterns of visual stimuli in the tail rapidly habituate and may not respond after several (one to eight) presentations of the same stimuli (Caan et al., 1984).

The DOA task is a working memory task, but it also requires discrimination between objects, a property shared with the VD task. Its main locus of activation was found in the posterior portion of the body of the caudate nucleus, at a distance from the significant locus of activation of the spatial working memory task. From a functional standpoint, this finding indicates that visual processing in the DOA task may override the working memory component, again favoring the concept of a topographic segrega- 

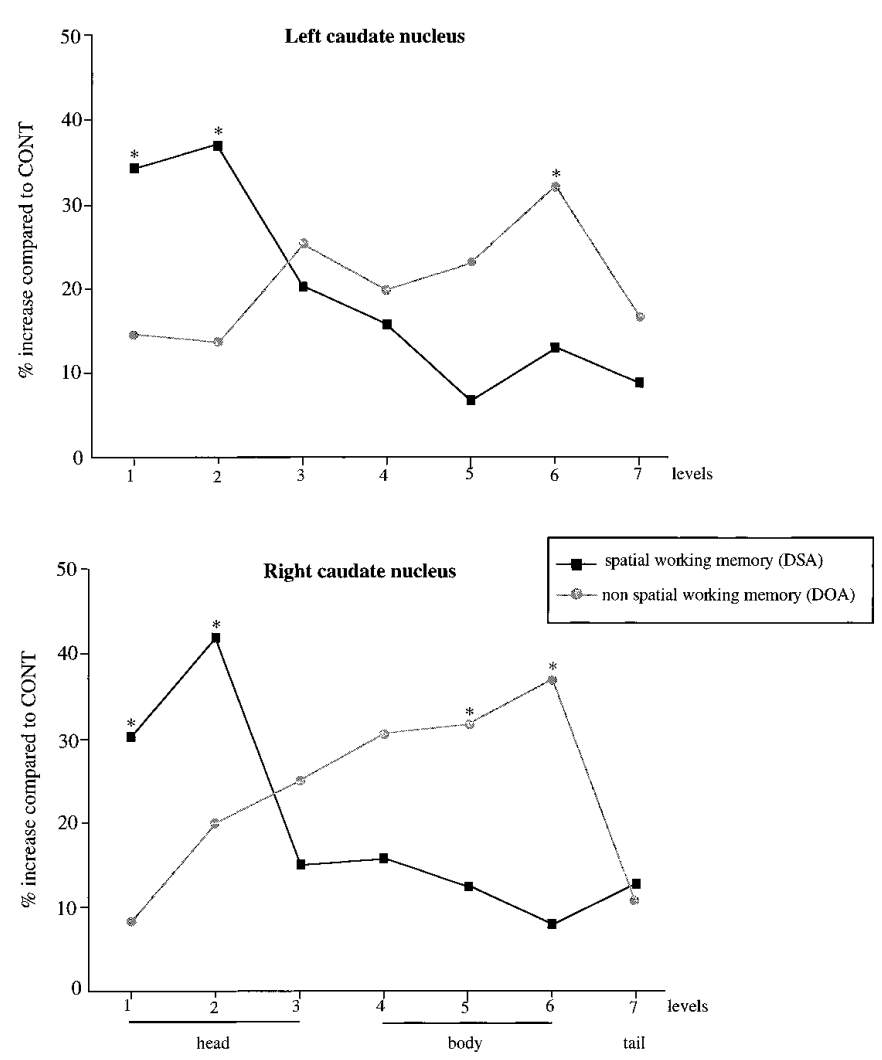

Figure 7. Gradient of changes throughout the anterior-posterior axis of the caudate nucleus in the spatial and nonspatial working memory groups, as compared with a control group. The results presented are the percent increase in adjusted mean LCGU rates in the spatial and nonspatial working memory conditions, as compared with a control group (VD + SMC tasks) for the left (top) and right (bottom) caudate nuclei. Statistically significant increases in mean LCGU rates $(p<0.05)$ are shown by the asterisks.

tion of functions within the striatum according to distinct sensory processing domains (object and spatial domains). However, because the orbital prefrontal (Walker's areas 13, 25, 32) and inferolateral prefrontal regions (Walker's area 12) project to the ventral regions of the caudate nucleus (Van Hoesen et al., 1981; Selemon and Goldman-Rakic, 1985; Yeterian and Pandya, 1991; Haber et al., 1995), these regions might be expected to be significantly activated by the DOA task. Instead, we found significant LCGU enhancement confined to the intermediate and posterior portions of the body of the caudate nuclei and not in its ventral regions. Although lesions of this sector have been shown to produce deficits in several nonspatial cognitive tasks (Divac et al., 1967; Butters and Rosvold, 1968), no previous study has used a working memory task such as the DOA. Moreover, the caudate region activated by this task receives afferents from the inferotemporal cortex (see above for references), which has been implicated in nonspatial short-term memory (Miyashita and Chang, 1988; Miller and Desimone, 1993). Thus, our results are the first to demonstrate a specific striatal locus involved in nonspatial working memory in posterior regions of the caudate nucleus.

In spite of the task-dependent segregation of activation, the present results do not support a complete and clear-cut double dissociation between spatial and nonspatial working memory subregions. First, the spatial and nonspatial working memory tasks as well as the nonspatial associative memory task co-activate the very same region of the caudate nucleus (the caudal portion of the body). Second, the fact that in every caudate subregion, the LCGU rates in the memory conditions were always found to be above the levels of the SMC task indicates that neurons participating in spatial or nonspatial working memory are not only restricted to the significant loci of activation but also distributed widely throughout the rostro-caudal axis. Moreover, the two working memory groups did not differ statistically at any level studied. These data indicate that the significant loci of activation were only the epicenters of larger areas of activation and pinpoint the probability that neurons at a distance from the main sites of activation participate in these cognitive processes as well. This proposal supports the existence of functional elongated rostrocaudal strips that may be approximately superimposed onto the previously described longitudinal strips of corticostriatal projections (Selemon and Goldman-Rakic, 1985).

\section{Clinical considerations}

Clinical observations in patients with Parkinson's disease (PD), Huntington's disease (HD), or direct striatal lesions have provided insights into the role of the striatum in cognition. In the early phases of PD, when the disease likely produces an isolated striatal dysfunction, a prefrontal-like cognitive syndrome is often found (Lees and Smith, 1983; Cooper et al., 1991). Moreover, nondemented PD patients exhibit impairments in working memory tasks (Freedman and Oscar Berman, 1986; Bradley et al., 1989; Owen et al., 1992; Postle et al., 1995; Gabrieli et al., 1996; Partiot et al., 1996) as well as in numerous other related or derivative executive functions such as planning, problem solving, formation of concepts, shifting abilities, temporal ordering, categorization, and self-generation of strategies for the retrieval of stored information (for review, see Dubois et al., 1991). In early stages of HD, when the neuronal loss affects primarily the mediodorsal portion of the caudate nucleus and spares the cerebral cortex (Vonsattel et al., 1985), a prefrontal dysfunction (Brandt, 1991) including a deficit in spatial working memory (Oscar Berman et al., 1982; Lawrence et al., 1995) is likely to be seen as well. Finally, unilateral or bilateral vascular lesions restricted to the head of the caudate nucleus induce aboulia, resulting in the reduction of spontaneous thoughts, initiative, and motor activity (Bhatia and Marsden, 1994). Direct lesions of the prefrontal cortex can also produce aboulia (Luria, 1966). Altogether, these studies have provided an overwhelming body of evidence in support of the role of the caudate nucleus in prefrontal-like functions. The present findings extend this evidence by establishing the contribution of the striatum, especially the head of the caudate nucleus, to working memory.

Patients with PD and HD also exhibit impairments in operations not classically associated with prefrontal cortex such as VD, conditional associative learning, pattern recognition memory, and spatial discrimination (Brandt, 1991; Dubois et al., 1991). As discussed above, it has been shown in monkeys that tasks engaging associative memory may activate specific subregions of the striatum. The present evidence that the VD task produces a significant LCGU enhancement in a posterior portion of the caudate nucleus supports further the concept that the role of the nucleus in cognition is related to the cortical area with which it is most intensively anatomically connected.

If the concept of working memory is taken in the broad sense of a fundamental process for elaborating coherent ideas (maintaining thoughts, temporally binding them, planning sequences of thoughts or actions) (Goldman-Rakic, 1987), many of the dysfunctions of cognitive processes (namely, the "executive," "mem- 
ory," and "visuospatial" functions) observed in basal ganglia diseases may reflect in part a deficit in working memory. Thus, It may be of great interest to better delineate the specific contribution of caudate neurons to working memory and to elucidate further the relative segregation of spatial and nonspatial working memory networks within the striatum.

\section{REFERENCES}

Albert ML, Feldman RG, Willis AL (1974) The "subcortical dementia" of progressive supranuclear palsy. J Neurol Neurosurg Psychiatry 37:121-130.

Alexander GE, Delong MR, Strick PL (1986) Parallel organization of functionally segregated circuits linking basal ganglia and cortex. Annu Rev Neurosci 9:357-381.

Apicella P, Scarnati E, Ljungberg T, Schultz W (1992) Neuronal activity in monkey striatum related to the expectation of predictable environmental events. J Neurophysiol 68:945-960.

Battig K, Rosvold HE, Mishkin M (1960) Comparison of the effect of frontal and caudate lesions on delayed response and alternation in monkeys. J Comp Physiol Psychol 53:400-404.

Bhatia KP, Marsden CD (1994) The behavioural and motor consequences of focal lesions of the basal ganglia in man. Brain 117:859-876.

Bradley VA, Welch JL, Dick DJ (1989) Visuospatial working memory in Parkinson's disease. J Neurol Neurosurg Psychiatry 52:1228-1235.

Brandt J (1991) Cognitive impairments in Huntington's disease: insights into the neuropsychology of the striatum. In: Handbook of neuropsychology (Boller F, Grafman J, eds), pp 241-264. Amsterdam: Elsevier.

Buerger AA, Gross CG, Rocha-Miranda CE (1974) Effects of ventral putamen lesions on discrimination learning by monkeys. J Comp Physiol Psychol 86:440-446.

Butters N, Rosvold HE (1968) Effect of caudate and septal nuclei lesions on resistance to extinction and delayed alternation. J Comp Physiol Psychol 65:397-403.

Caan W, Perrett DI, Rolls ET (1984) Responses of striatal neurons in the behaving monkey. II. Visual processing in the caudal neostriatum. Brain Res 290:53-65.

Cavada C, Goldman-Rakic PS (1991) Topographic segregation of corticostriatal projections from posterior parietal subdivisions in the macaque monkey. Neuroscience 42:683-696.

Cohen SM (1972) Electrical stimulation of cortical-caudate pairs during delayed successive visual discrimination in monkeys. Acta Neurobiol Exp (Warsz) 32:1271-1273.

Cooper JA, Sagar HJ, Jordan N, Harvey NS, Sullivan EV (1991) Cognitive impairment in early untreated Parkinson's disease and its relationship to motor disability. Brain 114:2095-2122.

Courtney SM, Ungerleider LG, Keil K, Haxby JV (1996) Object and spatial working memory activate separate neural systems in human cortex. Cereb Cortex 6:39-49.

Davachi L, Friedman HR, Goldman-Rakic PS (1995) Increased metabolic activity in the entorhinal and perirhinal cortices and subiculum in monkeys performing working memory tasks as revealed by the 2-deoxyglucose method. Soc Neurosci Abstr 21:1447.

Divac I, Rosvold HE, Scwarcbart MK (1967) Behavioural effects of selective ablation of the caudate nucleus. J Comp Physiol Psychol 63:184-190.

Dubois B, Boller F, Pillon B, Agid Y (1991) Cognitive deficits in Parkinson's disease. In: Handbook of neuropsychology (Boller F, Grafman J, eds), pp 195-240. Amsterdam: Elsevier.

Eblen F, Graybiel AM (1995) Highly restricted origin of prefrontal cortical inputs to striosomes in the macaque monkey. J Neurosci 15:5999-6013.

Freedman M, Oscar-Berman M (1986) Selective delayed response deficits in Parkinson's and Alzheimer's disease. Arch Neurol 43:886-890.

Friedman HR, Goldman-Rakic PS (1988) Activation of the hippocampus and dentate gyrus by working memory: a 2-deoxyglucose study of behaving rhesus monkeys. J Neurosci 8:4693-4706.

Friedman HR, Goldman-Rakic PS (1994) Coactivation of prefrontal cortex and inferior parietal cortex in working memory tasks revealed by 2DG functional mapping in the rhesus monkey. J Neurosci 14:2775-2788.

Friedman HR, Janas J, Goldman-Rakic PS (1990) Enhancement of metabolic activity in the diencephalon of monkeys performing working memory tasks: a 2-deoxyglucose study in behaving monkeys. J Cognit Neurosci 2:18-31.
Fuster J (1989) The prefrontal cortex, Ed 2. New York: Raven.

Gabrieli JDE, Singh J, Stebbins GT, Goetz CG (1996) Reduced working memory span in Parkinson's disease: evidence for the role of a fronto striatal system in working memory and strategic memory. Neuropsychology 10:322-332.

Gellerman LW (1933) Chance orders of alternating stimuli in visual discrimination experiments. J Gen Psychol 42:207-208.

Goldman PS, Rosvold HE, Vest B, Galkin TW (1971) Analysis of the delayed-alternation deficit produced by dorsolateral prefrontal lesions in the rhesus monkey. J Comp Physiol Psychol 77:212-220.

Goldman-Rakic PS (1987) Circuitry of primate prefrontal cortex and regulation of behavior by representational memory. In: Handbook of physiology, Vol 5 (Plum F, Mouncastle U, eds), pp 373-417. Washington, DC: The American Physiological Society.

Goldman-Rakic PS, Nauta WJH (1977) An intricately patterned prefronto-caudate projection in the rhesus monkey. J Comp Neurol 171:369-386.

Haber SN, Kunishio K, Mizobuchi M, Lynd-Balta E (1995) The orbital and medial prefrontal circuit through the primate basal ganglia. J Neurosci 15:4851-4867.

Hikosaka O, Sakamoto M, Usui S (1989) Functional properties of monkey caudate neurons. III. Activities related to expectation of target and reward. J Neurophysiol 61:814-832.

Jonides J, Smith EE, Koeppe RA, Awh E, Minoshima S, Mintun MA (1993) Spatial working memory in humans as revealed by PET. Nature 363:623-625.

Kemp JM, Powell TPS (1970) The cortico-striate projections in the monkey. Brain 93:525-546.

Kennedy C, Sakaruda O, Shinohara M, Jehle J, Sokoloff L (1978) Local glucose utilization in the normal conscious macaque monkey. Ann Neurol 4:293-301.

Lawrence AD, Sahakian BJ, Hodges JR, Lange KW, Robbins TW (1995) An examination of executive and mnemonic functions in mild Huntington's disease. Soc Neurosci Abstr 21:490.

Lees AJ, Smith E (1983) Cognitive deficits in the early stages of Parkinson's disease. Brain 106:257-270.

Luria AR (1966) Higher cortical functions in man. New York: Basic Books.

McCarthy G, Blamire AM, Puce A, Nobre AC, Bloch G, Hyder F, Goldman-Rakic PS, Shulman RG (1994) Functional magnetic resonance imaging of human prefrontal cortex activation during a spatial working memory task. Proc Natl Acad Sci USA 91:8690-8694.

Miller EK, Desimone R (1993) Activity of neurons in anterior inferior temporal cortex during a short-term memory task. J Neurosci 13:1460-1478.

Milner B (1964) Some effects of frontal lobectomy in man. In: The frontal granular cortex and behaviour (Warren JM, Akert K, eds), pp 313-334. New York: McGraw-Hill.

Mitchell IJ, Clarke CE, Boyce S, Robertson RG, Peggs D, Sambrook MA, Crossman AR (1989) Neural mechanisms underlying parkinsonian symptoms based upon regional uptake of 2-deoxyglucose in monkeys exposed to 1-methyl-4-phenyl-1,2,3,6-tetrahydropyridine. Neuroscience 32:213-226.

Miyashita Y, Chang HS (1988) Neuronal correlate of pictorial short-term memory in the primate temporal cortex. Nature 331:68-70.

Oscar-Berman M, Zola-Morgan SM, Oberg RGE, Bonner RT (1982) Comparative neuropsychologia and Korsakoff's syndrome. III. Delayed response, delayed alternation, and DRL performance. Neuropsychologia 20:187-202.

Owen AM, James M, Leigh PN, Summers BA, Marsden CD, Quinn NP, Lange KW, Robbins TW (1992) Fronto-striatal cognitive deficits at different stages of Parkinson's disease. Brain 115:1727-1751.

Owen AM, Doyon J, Petrides M, Evans AC (1996a) Planning and spatial working memory: a positron emission tomography study in humans. Eur J Neurosci 8:353-364.

Owen AM, Evans AC, Petrides M (1996b) Evidence for a two-stage model of spatial working memory processing within the lateral frontal cortex: a positron emission study. Cereb Cortex 6:31-38.

Partiot A, Verin M, Pillon B, Teixeira-Ferreira C, Agid Y, Dubois B (1996) Delayed response tasks in basal ganglia lesions in man: further evidence for a striato-frontal cooperation in behavioural adaptation. Neuropsychologia 34:709-721.

Petrides M, Alivisatos B, Evans AC, Meyer E (1993) Dissociation of human mid-dorsolateral from posterior dorsolateral frontal cortex in memory processing. Proc Natl Acad Sci USA 90:873-877. 
Pillon B, Dubois B, Lhermitte F, Agid Y (1986) Heterogeneity of cognitive impairments in progressive supranuclear palsy, Parkinson's disease and Alzheimer's disease. Neurology 36:1179-1185.

Postle BR, Jonides J, Smith E, Corkin S, Growdon JH (1995) Selective vulnerability of spatial delayed response in early Parkinson's disease. Soc Neurosci Abstr 21:755.

Rolls ET (1994) Neurophysiology and cognitive functions of the striatum. Rev Neurol (Paris) 150:648-660.

Rosvold HE, Mishkin M, Szwarbach MK (1958) Effects of subcortical lesions in monkeys on visual-discrimination and single-alternation performance. J Comp Physiol Psychol 51:437-444.

Saint-Cyr JA, Ungerleider LG, Desimone R (1990) Organization of visual cortical inputs to the striatum and subsequent outputs to the pallido-nigral complex in the monkey. J Comp Neurol 298:129-156.

Schallice T (1982) Specific impairments in planning. Philos Trans R Soc Lond [Biol] 298:199-209.

Schultz W, Romo R (1988) Neuronal activity in the monkey striatum during the initiation of movements. Exp Brain Res 71:431-436.

Schwartz WJ, Smith CB, Davidsen L, Sakavi H, Sokoloff L, Mata M, Fink DJ, Gainer H (1979) Metabolic mapping of functional activity in the hypothalamo-neurohypophysial system of the rat. Science 205:723-725.

Selemon LD, Goldman-Rakic PS (1985) Longitudinal topography and interdigitation of corticostriatal projections in the rhesus monkeys. J Neurosci 5:776-794.

Smith EE, Jonides J, Koeppe RA, Awh E, Schumacher E, Minoshima S (1995) Spatial vs object working memory: PET investigations. J Cognit Neurosci 7:337-358.

Smith EE, Jonides J, Koeppe RA (1996) Dissociating verbal and spatial working memory using PET. Cereb Cortex 6:11-20.
Sokoloff L, Reivich M, Kennedy C, Desrosiers MH, Patlak CS, Petigrew KD, Shakudara O, Shinohara M (1977) The 14C-deoxyglucose method for measurement of local cerebral glucose utilization: theory, procedure, and normal values in the conscious and anesthetized albino rat. J Neurochem 28:897-916.

Steele GE, Weller RE (1993) Subcortical connections of subdivisions of inferior temporal cortex in squirrel monkeys. Vis Neurosci 10:563-583.

Taylor AE, Saint-Cyr JA, Lang AE (1986) Frontal lobe dysfunction in Parkinson's disease. Brain 109:845-883.

Van Hoesen GW, Yeterian EH, Lavizzo-Mourney R (1981) Widespread cortico-striate projections from temporal cortex of the rhesus monkey. J Comp Neurol 199:205-219.

Vonsattel JP, Myers RH, Stevens TJ, Ferrante RJ, Bird ED, Richardson EP (1985) Neuropathological classification of Huntington's disease. J Neuropathol Exp Neurol 44:559-577.

Webster MJ, Bachevalier J, Ungerleider LG (1993) Subcortical connections of inferior temporal areas TE and TEO in macaque monkeys. J Comp Neurol 335:73-91.

Yarowsky P, Crane A, Sokoloff L (1985) Metabolic activation of specific postsynaptic elements in superior cervical ganglion by antidromic stimulation of external carotid nerve. Brain Res 334:330-334.

Yeterian EH, Pandya DN (1991) Prefrontostriatal connections in relation to cortical architectonic organization in rhesus monkeys. J Comp Neurol 312:43-67.

Yeterian EH, Pandya DN (1995) Corticostriatal connections of extrastriate visual areas in rhesus monkeys. J Comp Neurol 352:436-457.

Yeterian EH, Van Hoesen GW (1978) Cortico-striate projections in the rhesus monkey: the organization of certain cortico-caudate connections. Brain Res 139:43-63. 